\title{
Monitoring of aphid flights associated with vegetation of allotments in Poznań
}

\section{Monitoring lotów mszyc związanych z roślinnością ogrodów działkowych Poznania}

\author{
Barbara Wilkaniec $^{1 *}$, Beata Borowiak-Sobkowiak ${ }^{1}$, Marta Rzańska-Wieczorek ${ }^{1,2}$
}

\begin{abstract}
Summary
Allotments are important element of urban greenery. The garden vegetation enables the development of many groups of animals, including insects. The urban conditions there are especially good for development of aphids. This paper presents the aphid flights with using of Moericke traps method. Three of allotments were monitoring in Poznań. The activity of 114 aphid species was found in 2014-2015. Seasonal abundance of aphids and aphid composition were different between the years. There were 22 aphid species in all localities and years of studies. The bird cherry-oat aphid (Rhopalosiphum padi) and the dogwood-grass aphid (Anoecia corni) were the most numerous from all the species caught.
\end{abstract}

Key words: aphids; flight activity; urban greenery; Rhopalosiphum padi; Anoecia corn

\section{Streszczenie}

Ogrody działkowe są między innymi ważnym elementem miejskich terenów zieleni. Ich roślinność umożliwia rozwój wielu grup zwierząt, w tym również owadów. Mszyce w warunkach miejskich znajdują szczególnie dobre warunki rozwoju. Praca prezentuje wyniki badań dotyczące monitoringu morf uskrzydlonych mszyc w 3 ogrodach działkowych na terenie Poznania z wykorzystaniem metody pułapek Moerickego. W latach 2014-2015 stwierdzono aktywność 114 gatunków mszyc. Sezony różniły się między sobą liczebnością oraz składem gatunkowym afidofauny. 22 gatunki mszyc były obecne na wszystkich stanowiskach i w latach badań. Najliczniej odławianymi gatunkami były: mszyca czeremchowo-zbożowa (Rhopalosiphum padi) i zrostek świdwowo-zbożowy (Anoecia corni).

Słowa kluczowe: mszyce; aktywność lotów; miejskie tereny zieleni; Rhopalosiphum padi; Anoecia corni

\footnotetext{
${ }^{1}$ Uniwersytet Przyrodniczy w Poznaniu Katedra Entomologii i Ochrony Środowiska Dąbrowskiego 159, 60-594 Poznań

${ }^{2}$ Instytut Ochrony Roślin - Państwowy Instytut Badawczy

Zakład Biologicznych Metod

Władysława Węgorka 20, 60-318 Poznań

*corresponding author: wilk@up.poznan.pl
} 


\section{Wstęp / Introduction}

Ogrody działkowe obok parków, skwerów i zieleni osiedlowej stanowią ważny element miejskich terenów zieleni. Dzięki bogatej i zróżnicowanej roślinności umożliwiają rozwój wielu gatunkom zwierząt, w tym owadom. Stare ogrody działkowe Poznania, często o 90-letniej historii, tworzone pierwotnie na peryferiach miasta, obecnie obrosły „tkanką” miejską i podlegają silnej antropopresji. Zmienia się także sposób ich użytkowania z pierwotnie typowo produkcyjnego $\mathrm{z}$ uprawą warzyw oraz drzew i krzewów owocowych na rekreacyjny. Pociąga to za sobą zmianę w składzie roślinności tych obiektów, gdzie w ostatnich latach dominującą rolę odgrywają drzewa i krzewy ozdobne oraz trawniki. Srodowisko miast stwarza specyficzne warunki, często wysoko niekorzystne dla wzrostu i rozwoju roślinności, natomiast sprzyjające rozwojowi niektórych grup owadów. W zieleni miejskiej dotyczy to szczególnie stawonogów o kłująco-ssących narządach gębowych, do których należą mszyce. Dowodzą tego liczne krajowe opracowania afidofauny zieleni miast (Cichocka i Goszczyński 1991; Jaśkiewicz 1997; Wilkaniec 1999, 2001, 2004; Ruszkowska i Wilkaniec 2002; Wilkaniec i wsp. 2007; Bennewicz 2010; Ratajczak i wsp. 2011; Mackoś-Iwaszko i wsp. 2015). Brak natomiast informacji dotyczącej fauny mszyc, szczególnie ważnej grupy agrofagów, towarzyszącej zieleni ogrodów działkowych, powodującej szkody bezpośrednie przez wysysanie soków z roślin oraz pośrednie jako wektory wielu groźnych wirusów.

Celem badań była ocena składu gatunkowego oraz liczebności fauny mszyc zasiedlających roślinność ogrodów działkowych Poznania na podstawie aktywności lotów morf uskrzydlonych.

\section{Materiały i metody / Materials and methods}

Badania prowadzono na terenie ogrodów działkowych położonych w dwóch dzielnicach Poznania: Stare Miasto i Wilda, w latach 2014-2015. Były to trzy Rodzinne Ogrody Działkowe (ROD): ROD im. gen. Henryka Dąbrowskiego, ROD Urodzaj i ROD Bielniki. ROD im. gen. Henryka Dąbrowskiego mieszczący się przy ul. Piątkowskiej istnieje od 1930 roku i zajmuje powierzchnię 4,85 ha, podzieloną na 100 działek. ROD Urodzaj przy ul. Serbskiej powstał w 1949 roku i obejmuje 121 działek o łącznej powierzchni 3,8 ha. Najstarszy i największy ROD Bielniki położony przy Drodze Dębińskiej powstał w 1925 roku i zajmuje powierzchnię 21,3 ha. Obecnie na terenie ogrodów w coraz mniejszym zakresie prowadzi się uprawę warzyw i roślin sadowniczych na korzyść ozdobnych roślin ogrodniczych: bylin, drzew i krzewów. Mszyce odławiano metodą pułapek Moerickego, stosując 10 naczyń w każdym stanowisku, umieszczonych na wysokości $1,5 \mathrm{~m}$. Żółte naczynia o średnicy $18 \mathrm{~cm}$ i wysokości $11 \mathrm{~cm}$ wypełniono roztworem glikolu $\mathrm{z}$ dodatkiem detergentu. Odłowy morf uskrzydlonych mszyc prowadzono przez cały sezon wegetacyjny od kwietnia do października, pobierając próby $\mathrm{w}$ odstępach dekadowych. Owady przechowywano w 75\% alkoholu etylowym do czasu ich oznaczenia. Materiał oznaczono za pomocą kluczy Taylora (1984) oraz Blackmana i Eastopa (1994). Przyjęto następujące klasy dominacji za Durak i Wojciechowskim (2008): eudominanty $>20 \%$, dominanty 10-20\%, subdominanty - 5-10\% zebranego materiału w zgrupowaniu mszyc.

\section{Wyniki i dyskusja / Results and discussion}

Wyniki badań dowodzą aktywności bogatej fauny mszyc towarzyszącej roślinności ogrodów działkowych Poznania. W ciągu dwóch sezonów wegetacyjnych, w latach 2014-2015 łącznie do pułapek Moerickego trafiło 114 gatunków lub grup gatunków mszyc, przedstawicieli 2 rodzin: Adelgidae i Aphididae z 7 podrodzinami: Adelginae, Eriosomatinae, Anoeciinae, Mindarinae, Drepanosiphinae, Aphidinae i Lachninae. Najliczniej były reprezentowane dwie podrodziny: Aphidinae przez 78 gatunków i Drepanosiphinae przez 20 taksonów (tab. 1).

Poszczególne sezony badawcze i stanowiska różniły się między sobą liczebnością zebranych osobników oraz w mniejszym stopniu składem gatunkowym. Większą aktywność lotów mszyc obserwowano w sezonie 2014 roku, kiedy to liczba odłowionych osobników kilkakrotnie (3-6 razy) przewyższała liczbę zgromadzonego materiału w roku następnym (tab. 1). Największą intensywność lotów obserwowano w ROD im. gen. Henryka Dąbrowskiego w 2014 roku, kiedy do pułapek trafiły 4603 uskrzydlone morfy, najmniejszą w ROD Urodzaj w 2015 roku kiedy odłowiono zaledwie 424 mszyce. Z liczebnością odłowionych osobników wiązało się bogactwo fauny. Największą jej różnorodność stwierdzono w ROD im. gen. Henryka Dąbrowskiego, gdzie potwierdzono obecność 73 taksonów w 2014 roku, najmniejszą w ROD Urodzaj 48 gatunków w sezonie 2015 roku (tab. 1). Duże wahania w liczebności fauny mszyc między sezonami należy tłumaczyć wpływem warunków pogodowych na wielkość populacji mszyc. Sezon 2015 roku, z długimi okresami upałów w okresie lata, jako sezon najcieplejszy od 150 lat, od kiedy notuje się systematycznie dane meteorologiczne, był niesprzyjający dla ich rozwoju. Podobne różnice międzysezonowe obserwowano we wcześniejszych badaniach Wilkaniec (2001, 2004).

Badania dowiodły obecności 22 taksonów mszyc na wszystkich stanowiskach i w obu latach badań. Na tej podstawie uznano je za charakterystyczne dla roślinności ogrodów. Wśród nich znalazły się dwie grupy gatunków: pierwsza - ważne gospodarczo gatunki uznawane powszechnie za groźne szkodniki roślin uprawnych i druga gatunki dendrofilne, licznie zasiedlające drzewa i krzewy ozdobne w miastach. Do pierwszej grupy należy zaliczyć: mszycę burakową (Aphis fabae Scopoli, 1763), mszycę brzoskwiniową (Myzus persicae Sulzer, 1776), mszycę czeremchowo-zbożową (Rhopalosiphum padi Linnaeus, 1758), zrostka świdwowo-zbożowego (Anoecia corni Fabricius, 1775), mszycę lucernowo-grochodrzewową (Aphis craccivora Koch, 1854), porazika kocankowego (Brachycaudus helichrysi Kaltenbach, 1843), mszycę wierzbowo-marchwiową (Cavariella aegopodii Scopoli, 1763), porazika jabłoniowo-babkowego (Dysaphis plantaginea Passerini, 1860), mszycę śliwowo-trzcinową (Hyalopterus 
Tabela 1. Lista gatunków mszyc zebranych na terenie Rodzinnych Ogrodów Działkowych w Poznaniu w latach 2014-2015

Table 1. List of aphid species collected in the family allotments in Poznań in 2014-2015

\begin{tabular}{|c|c|c|c|c|c|c|}
\hline \multirow{3}{*}{ Gatunek - Species } & \multicolumn{6}{|c|}{ Rodzinne Ogrody Działkowe - Family alloments } \\
\hline & \multicolumn{2}{|c|}{$\begin{array}{l}\text { im. gen. Henryka } \\
\text { Dąbrowskiego }\end{array}$} & \multicolumn{2}{|c|}{ Urodzaj } & \multicolumn{2}{|c|}{ Bielniki } \\
\hline & 2014 & 2015 & 2014 & 2015 & 2014 & 2015 \\
\hline 1 & 2 & 3 & 4 & 5 & 6 & 7 \\
\hline $\begin{array}{l}\text { Mszyca grochowa } \\
\text { Acyrthosiphum pisum (Harris) }\end{array}$ & $\bullet$ & $\bullet$ & & & $\bullet$ & \\
\hline $\begin{array}{l}\text { Ochojnik } \\
\text { Adelges sp. }\end{array}$ & $\bullet$ & $\bullet$ & $\bullet$ & $\bullet$ & & $\bullet$ \\
\hline Amphorophora gei (Börn.) & & $\bullet$ & & & & \\
\hline $\begin{array}{l}\text { Mszyca malinianka } \\
\text { Amphorophora idaei (Börn.) }\end{array}$ & $\bullet$ & $\bullet$ & & & $\bullet$ & $\bullet$ \\
\hline $\begin{array}{l}\text { Zrostek świdwowo-zbożowy } \\
\text { Anoecia corni (F.) }\end{array}$ & $\bullet$ & $\bullet$ & $\bullet$ & $\bullet$ & $\bullet$ & $\bullet$ \\
\hline $\begin{array}{l}\text { Porazik podbiałowy } \\
\text { Anuraphis farfarae (Koch) }\end{array}$ & $\bullet$ & & $\bullet$ & & & \\
\hline $\begin{array}{l}\text { Porazik pasternakowy } \\
\text { Anuraphis subterranean (Walk.) }\end{array}$ & & & & $\bullet$ & & \\
\hline $\begin{array}{l}\text { Mszyca lucernowo-grochodrzewowa } \\
\text { Aphis craccivora Koch }\end{array}$ & $\bullet$ & $\bullet$ & $\bullet$ & $\bullet$ & $\bullet$ & $\bullet$ \\
\hline $\begin{array}{l}\text { Mszyca malinowa } \\
\text { Aphis idaei V.D. Goot }\end{array}$ & $\bullet$ & & & • & & $\bullet$ \\
\hline $\begin{array}{l}\text { Mszyca burakowa } \\
\text { Aphis fabae Scop. }\end{array}$ & $\bullet$ & $\bullet$ & $\bullet$ & $\bullet$ & $\bullet$ & $\bullet$ \\
\hline Aphis newtoni Theob. & $\bullet$ & & & & & \\
\hline $\begin{array}{l}\text { Mszyca jabłoniowa } \\
\text { Aphis pomi De Geer }\end{array}$ & $\bullet$ & $\bullet$ & $\bullet$ & $\bullet$ & $\bullet$ & \\
\hline $\begin{array}{l}\text { Mszyca bzowa } \\
\text { Aphis sambuci L. }\end{array}$ & $\bullet$ & $\bullet$ & $\bullet$ & - & $\bullet$ & $\bullet$ \\
\hline Aphis spp. & $\bullet$ & $\bullet$ & $\bullet$ & $\bullet$ & $\bullet$ & $\bullet$ \\
\hline Atheroides serrulatus Hal. & & & $\bullet$ & & & \\
\hline $\begin{array}{l}\text { Mszyca ziemniaczana } \\
\text { Aulacorthum solani (Kalt.) }\end{array}$ & $\bullet$ & & $\bullet$ & $\bullet$ & & $\bullet$ \\
\hline Aulacorthum speyeri & $\bullet$ & & & & & \\
\hline $\begin{array}{l}\text { Porazik ostowy } \\
\text { Brachycaudus cardui (L.) }\end{array}$ & $\bullet$ & $\bullet$ & $\bullet$ & & $\bullet$ & $\bullet$ \\
\hline Brachycaudus divaricatae Shap. & $\bullet$ & $\bullet$ & $\bullet$ & $\bullet$ & $\bullet$ & $\bullet$ \\
\hline $\begin{array}{l}\text { Porazik kocankowy } \\
\text { Brachycaudus helichrysi (Kalt.) }\end{array}$ & $\bullet$ & $\bullet$ & $\bullet$ & - & $\bullet$ & $\bullet$ \\
\hline $\begin{array}{l}\text { Porazik brzoskwiniowy } \\
\text { Brachycaudus schwartzi (Börn.) }\end{array}$ & & $\bullet$ & & $\bullet$ & & $\bullet$ \\
\hline Callipteriniella tuberculata (Heyd.) & $\bullet$ & & & & & \\
\hline Capitophorus elaeagni (Del Gu.) & - & & $\bullet$ & $\bullet$ & $\bullet$ & $\bullet$ \\
\hline Capitophorus horni Börn. & $\bullet$ & & & & & \\
\hline $\begin{array}{l}\text { Mszyca wierzbowo-marchwiowa } \\
\text { Cavariella aegopodii (Scop.) }\end{array}$ & $\bullet$ & $\bullet$ & $\bullet$ & $\bullet$ & $\bullet$ & $\bullet$ \\
\hline Cavariella archangelicae (Scop.) & & $\bullet$ & & & $\bullet$ & $\bullet$ \\
\hline $\begin{array}{l}\text { Mszyca wierzbowo-pasternakowa } \\
\text { Cavariella pastinaceae (L.) }\end{array}$ & & & & & & $\bullet$ \\
\hline Cavariella theobaldi (Gill. et Bragg) & $\bullet$ & & & & & \\
\hline Ceruraphis eriophori (Walk.) & $\bullet$ & & $\bullet$ & & $\bullet$ & \\
\hline Chaitophorus leucomelas Koch & $\bullet$ & $\bullet$ & $\bullet$ & $\bullet$ & $\bullet$ & • \\
\hline
\end{tabular}




\begin{tabular}{|c|c|c|c|c|c|c|}
\hline 1 & 2 & 3 & 4 & 5 & 6 & 7 \\
\hline $\begin{array}{l}\text { Włochatka topolowa pędowa } \\
\text { Chaitophorus populeti (Panz.) }\end{array}$ & $\bullet$ & $\bullet$ & $\bullet$ & & $\bullet$ & • \\
\hline $\begin{array}{l}\text { Włochatka topolowa biała } \\
\text { Chaitophorus populialbae (B. de F.) }\end{array}$ & $\bullet$ & • & $\bullet$ & & $\bullet$ & \\
\hline Chaetosiphon tetrarhodus (Walk.) & & $\bullet$ & & & & \\
\hline $\begin{array}{l}\text { Miodownica spadziowa } \\
\text { Cinara costata (Zett.) }\end{array}$ & & • & $\bullet$ & & & $\bullet$ \\
\hline $\begin{array}{l}\text { Miodownica żywotnikowa } \\
\text { Cinara cupressi (Buckt.) }\end{array}$ & & & & • & & \\
\hline $\begin{array}{l}\text { Miodownica jałowcowa } \\
\text { Cinara juniperi De Geer }\end{array}$ & & & & & $\bullet$ & \\
\hline $\begin{array}{l}\text { Miodownica długowłosa } \\
\text { Cinara pilicornis (Htg.) }\end{array}$ & $\bullet$ & $\bullet$ & $\bullet$ & $\bullet$ & & \\
\hline $\begin{array}{l}\text { Miodownica świerkowa } \\
\text { Cinara pruinosa (Htg.) }\end{array}$ & & $\bullet$ & & & & \\
\hline Cinara sp. & & & $\bullet$ & & & $\bullet$ \\
\hline Clethrobius comes (Walk.) & & & & & & $\bullet$ \\
\hline $\begin{array}{l}\text { Mszyca porzeczkowo-poziewnikowa } \\
\text { Cryptomyzus galeopsidis (Kalt.) }\end{array}$ & $\bullet$ & & & & & \\
\hline $\begin{array}{l}\text { Mszyca porzeczkowa alpejska } \\
\text { Cryptomyzus korschelti Börn. }\end{array}$ & $\bullet$ & & & $\bullet$ & & \\
\hline $\begin{array}{l}\text { Mszyca porzeczkowo-czyściecowa } \\
\text { Cryptomyzus ribis (L.) }\end{array}$ & $\bullet$ & & & & & \\
\hline $\begin{array}{l}\text { Mszyca ostróżkowa } \\
\text { Delphiniobium junankianum (Karsch) }\end{array}$ & $\bullet$ & & & & & \\
\hline Drepanosiphum aceris Koch & $\bullet$ & $\bullet$ & $\bullet$ & & $\bullet$ & $\bullet$ \\
\hline $\begin{array}{l}\text { Zdobniczka jaworowa } \\
\text { Drepanosiphum platanoidis (Schrk.) }\end{array}$ & $\bullet$ & $\bullet$ & $\bullet$ & $\bullet$ & $\bullet$ & $\bullet$ \\
\hline $\begin{array}{l}\text { Mszyca głogowo-marchwiowa } \\
\text { Dysaphis crataegi (Kalt.) }\end{array}$ & & & & $\bullet$ & & \\
\hline $\begin{array}{l}\text { Mszyca jabłoniowo-babkowa } \\
\text { Dysaphis plantaginea (Pass.) }\end{array}$ & $\bullet$ & $\bullet$ & $\bullet$ & $\bullet$ & $\bullet$ & $\bullet$ \\
\hline Dysaphis sp. & $\bullet$ & & $\bullet$ & & $\bullet$ & \\
\hline $\begin{array}{l}\text { Mszyca świerkowo-szpilkowa } \\
\text { Elatobium abietinum (Walk.) }\end{array}$ & $\bullet$ & $\bullet$ & $\bullet$ & $\bullet$ & $\bullet$ & $\bullet$ \\
\hline $\begin{array}{l}\text { Bawełnica wiązowo-porzeczkowa } \\
\text { Eriosoma ulmi (L.) }\end{array}$ & $\bullet$ & $\bullet$ & $\bullet$ & $\bullet$ & $\bullet$ & $\bullet$ \\
\hline $\begin{array}{l}\text { Zdobniczka lipowa } \\
\text { Eucallipterus tiliae (L.) }\end{array}$ & $\bullet$ & $\bullet$ & $\bullet$ & & $\bullet$ & $\bullet$ \\
\hline Euceraphis betulae (Koch) & $\bullet$ & $\bullet$ & $\bullet$ & $\bullet$ & $\bullet$ & $\bullet$ \\
\hline Euceraphis punctipennis (Zett.) & $\bullet$ & & & & $\bullet$ & \\
\hline Eulachnus rileyi (Will.) & & & & & & $\bullet$ \\
\hline Hayhurstia atriplicis (L.) & & $\bullet$ & & & & $\bullet$ \\
\hline $\begin{array}{l}\text { Mszyca wiciokrzewowo-baldachowa } \\
\text { Hyadaphis foeniculi (Pass.) }\end{array}$ & & & & $\bullet$ & $\bullet$ & $\bullet$ \\
\hline $\begin{array}{l}\text { Mszyca śliwowo-trzcinowa } \\
\text { Hyalopterus pruni (Geoff.) }\end{array}$ & $\bullet$ & $\bullet$ & $\bullet$ & $\bullet$ & $\bullet$ & $\bullet$ \\
\hline $\begin{array}{l}\text { Mszyca porzeczkowo-mleczowa } \\
\text { Hyperomyzus lactucae (L.) }\end{array}$ & $\bullet$ & $\bullet$ & $\bullet$ & $\bullet$ & $\bullet$ & $\bullet$ \\
\hline Hyperomyzus lampsanae (Börn.) & $\bullet$ & & & $\bullet$ & & \\
\hline $\begin{array}{l}\text { Mszyca agrestowo-mleczowa } \\
\text { Hyperomyzus pallidus H.R.L. }\end{array}$ & $\bullet$ & & & & & \\
\hline $\begin{array}{l}\text { Mszyca porzeczkowo-goryczkowa } \\
\text { Hypromyzus picridis (Börn.) }\end{array}$ & $\bullet$ & & $\bullet$ & & $\bullet$ & $\bullet$ \\
\hline
\end{tabular}




\begin{tabular}{|c|c|c|c|c|c|c|}
\hline 1 & 2 & 3 & 4 & 5 & 6 & 7 \\
\hline Impatietientinum asiaticum Nevsky & $\bullet$ & & $\bullet$ & & & \\
\hline $\begin{array}{l}\text { Mszyca kwaśnicowa } \\
\text { Liosomaphis berberidis (Kalt.) }\end{array}$ & $\bullet$ & $\bullet$ & & & & \\
\hline $\begin{array}{l}\text { Mszyca kapustnica wielożerna } \\
\text { Lipaphis erysimi (Kalt.) }\end{array}$ & & - & & $\bullet$ & $\bullet$ & $\bullet$ \\
\hline $\begin{array}{l}\text { Mszyca różano-rutewkowa } \\
\text { Longicaudus thrihodus (Walk.) }\end{array}$ & & & $\bullet$ & & & \\
\hline Macrosiphoniella tanacetaria (Kalt.) & & & & & & $\bullet$ \\
\hline Macrosiphoniella sp. & $\bullet$ & $\bullet$ & $\bullet$ & & & $\bullet$ \\
\hline $\begin{array}{l}\text { Mszyca ziemniaczana smugowa } \\
\text { Macrosiphum euphorbiae (Thom.) }\end{array}$ & & $\bullet$ & $\bullet$ & $\bullet$ & $\bullet$ & $\bullet$ \\
\hline $\begin{array}{l}\text { Mszyca różano-szczeciowa } \\
\text { Macrosiphum rosae (L.) }\end{array}$ & $\bullet$ & $\bullet$ & $\bullet$ & & $\bullet$ & $\bullet$ \\
\hline Megourella purpurea H.R.L. & & $\bullet$ & & & $\bullet$ & \\
\hline $\begin{array}{l}\text { Mszyca różano-trawowa } \\
\text { Metopolophium dirhodum (Walk.) }\end{array}$ & $\bullet$ & & $\bullet$ & & - & \\
\hline Microlophium carnosum (Buckt.) & $\bullet$ & $\bullet$ & $\bullet$ & & & \\
\hline Mimeuria ulmiphila (Del Gu.) & & & & & & $\bullet$ \\
\hline Mindarus abietinum Koch & $\bullet$ & & & & & \\
\hline $\begin{array}{l}\text { Zdobniczka kasztanowo-dębowa } \\
\text { Myzocallis castanicola Baker }\end{array}$ & $\bullet$ & $\bullet$ & & & & $\bullet$ \\
\hline $\begin{array}{l}\text { Mszyca szklarniowa wielożerna } \\
\text { Myzus ascalonicus (Donc.) }\end{array}$ & $\bullet$ & $\bullet$ & & $\bullet$ & & $\bullet$ \\
\hline $\begin{array}{l}\text { Mszyca wiśniowa } \\
\text { Myzus cerasi (F.) }\end{array}$ & $\bullet$ & $\bullet$ & $\bullet$ & $\bullet$ & $\bullet$ & $\bullet$ \\
\hline $\begin{array}{l}\text { Mszyca ligustrowa } \\
\text { Myzus ligustri Mosl. }\end{array}$ & $\bullet$ & $\bullet$ & $\bullet$ & & & $\bullet$ \\
\hline $\begin{array}{l}\text { Mszyca antypkowa } \\
\text { Myzus lythri (Schrk.) }\end{array}$ & & $\bullet$ & & & $\bullet$ & \\
\hline $\begin{array}{l}\text { Mszyca brzoskwiniowa } \\
\text { Myzus persicae (Sulz.) }\end{array}$ & $\bullet$ & $\bullet$ & $\bullet$ & $\bullet$ & $\bullet$ & $\bullet$ \\
\hline Nasonovia pilosellae (Börn.) & & $\bullet$ & & & & \\
\hline $\begin{array}{l}\text { Mszyca porzeczkowo-sałatowa } \\
\text { Nasonovia ribisnigri (Mosl.) }\end{array}$ & $\bullet$ & $\bullet$ & $\bullet$ & & & \\
\hline Neotrama caudate (Del. Gu.) & & $\bullet$ & & & & \\
\hline $\begin{array}{l}\text { Mszyca głogowo-miętowa } \\
\text { Ovatus crataegarius (Walk.) }\end{array}$ & $\bullet$ & & & & & \\
\hline Ovatus mentharius H.R.L. & & $\bullet$ & & $\bullet$ & & \\
\hline $\begin{array}{l}\text { Zdobniczka orzechowa } \\
\text { Panaphis juglandis (Goetze) }\end{array}$ & $\bullet$ & & $\bullet$ & & $\bullet$ & $\bullet$ \\
\hline Pemphigus sp. & $\bullet$ & & & & & \\
\hline Periphyllus acericola (Walk.) & & & & & $\bullet$ & \\
\hline Periphyllus aceris (L.) & $\bullet$ & $\bullet$ & & $\bullet$ & & \\
\hline Periphyllus californiensis (Shinji) & & $\bullet$ & & & & \\
\hline Periphyllus coracinus (Koch) & $\bullet$ & & & & & \\
\hline $\begin{array}{l}\text { Włochatka klonowa czarna } \\
\text { Periphyllus testudinaceus (Fern.) }\end{array}$ & $\bullet$ & $\bullet$ & $\bullet$ & $\bullet$ & $\bullet$ & $\bullet$ \\
\hline $\begin{array}{l}\text { Mszyca chmielowa } \\
\text { Phorodon humuli (Schrk.) }\end{array}$ & $\bullet$ & $\bullet$ & $\bullet$ & $\bullet$ & $\bullet$ & $\bullet$ \\
\hline $\begin{array}{l}\text { Zdobniczka bukowa } \\
\text { Phyllaphis fagi (L.) }\end{array}$ & & $\bullet$ & & $\bullet$ & $\bullet$ & $\bullet$ \\
\hline $\begin{array}{l}\text { Bawełnica jesionowa fałdująca } \\
\text { Prociphilus bumeliae (Schrk.) }\end{array}$ & $\bullet$ & $\bullet$ & & & $\bullet$ & \\
\hline
\end{tabular}




\begin{tabular}{|c|c|c|c|c|c|c|}
\hline 1 & 2 & 3 & 4 & 5 & 6 & 7 \\
\hline Prociphilus pini (Burm.) & & & $\bullet$ & & $\bullet$ & \\
\hline Protrama flavescens (Koch) & & & & & $\bullet$ & \\
\hline $\begin{array}{l}\text { Mszyca wierzbowa korowa } \\
\text { Pterocomma pilosum Buckt. }\end{array}$ & $\bullet$ & $\bullet$ & & & & $\bullet$ \\
\hline $\begin{array}{l}\text { Mszyca topolowa korowa } \\
\text { Pterocomma populeum (Kalt.) }\end{array}$ & $\bullet$ & $\bullet$ & & • & • & • \\
\hline $\begin{array}{l}\text { Mszyca wiciokrzewowo-trawowa } \\
\text { Rhopalomyzus lonicerae (Sieb.) }\end{array}$ & $\bullet$ & & & & $\bullet$ & $\bullet$ \\
\hline $\begin{array}{l}\text { Mszyca jabłoniowo-zbożowa } \\
\text { Rhopalosiphum insertum (Walk.) }\end{array}$ & $\bullet$ & & & & • & \\
\hline $\begin{array}{l}\text { Mszyca grzybieniowa } \\
\text { Rhopalosiphum nymphaeae (L.) }\end{array}$ & & $\bullet$ & & & & \\
\hline $\begin{array}{l}\text { Mszyca czeremchowo-zbożowa } \\
\text { Rhopalosiphum padi (L.) }\end{array}$ & $\bullet$ & $\bullet$ & $\bullet$ & • & • & $\bullet$ \\
\hline Schizolachnus pineti (F.) & & & & & & $\bullet$ \\
\hline $\begin{array}{l}\text { Mszyca malinowo-trawowa } \\
\text { Sitobion fragariae (Walk.) }\end{array}$ & $\bullet$ & & $\bullet$ & & $\bullet$ & \\
\hline $\begin{array}{l}\text { Mszyca zbożowa } \\
\text { Sitobion avenae (F.) }\end{array}$ & & • & $\bullet$ & $\bullet$ & & $\bullet$ \\
\hline $\begin{array}{l}\text { Bawełnica wiązowo-zbożowa } \\
\text { Tetraneura ulmi (L.) }\end{array}$ & $\bullet$ & $\bullet$ & $\bullet$ & $\bullet$ & $\bullet$ & $\bullet$ \\
\hline Therioaphis luteola (Börn.) & & & & & $\bullet$ & \\
\hline Tinocallis platani (Kalt.) & & $\bullet$ & & & & \\
\hline Trichosiphonaphis corticis (Aizenb.) & & $\bullet$ & & $\bullet$ & & \\
\hline Tubaphis ranunculina (Walk.) & & & & $\bullet$ & & \\
\hline Uroleucon $\mathrm{sp}$. & & $\bullet$ & & $\bullet$ & $\bullet$ & \\
\hline Uromelan sp. & $\bullet$ & $\bullet$ & & $\bullet$ & $\bullet$ & $\bullet$ \\
\hline Wahlgreniella ossiannilssoni H.L.R. & & & & $\bullet$ & & \\
\hline Liczba gatunków/rok - Number of species/year & 73 & 66 & 51 & 48 & 56 & 57 \\
\hline Liczba osobników/rok - Number of specimens/year & 4603 & 735 & 1318 & 424 & 2731 & 636 \\
\hline
\end{tabular}

Tabela 2. Gatunki mszyc o dużej aktywności lotów w ogrodach działkowych w Poznaniu w latach 2014-2015

Table 2. Aphid species with high flight activity in Poznań allotments in 2014-2015

\begin{tabular}{|c|c|c|c|c|c|c|}
\hline \multirow{3}{*}{ Gatunek - Species } & \multicolumn{6}{|c|}{ Stopień dominacji - Degree of dominance } \\
\hline & \multicolumn{2}{|c|}{$\begin{array}{c}\text { ROD im. gen. } \\
\text { Henryka Dąbrowskiego } \\
\text { „gen. H. Dąbrowski” allotments }\end{array}$} & \multicolumn{2}{|c|}{$\begin{array}{c}\text { ROD Urodzaj } \\
\text { „Urodzaj” allotments }\end{array}$} & \multicolumn{2}{|c|}{$\begin{array}{c}\text { ROD Bielniki } \\
\text { „Bielniki” allotments }\end{array}$} \\
\hline & 2014 & 2015 & 2014 & 2015 & 2014 & 2015 \\
\hline $\begin{array}{l}\text { Mszyca czeremchowo-zbożowa } \\
\text { Rhopalosiphum padi (L.) }\end{array}$ & +++ & ++ & +++ & ++ & +++ & +++ \\
\hline $\begin{array}{l}\text { Zrostek świdwowo-zbożowy } \\
\text { Anoecia corni (F.) }\end{array}$ & & + & + & +++ & & + \\
\hline $\begin{array}{l}\text { Zdobniczka jaworowa } \\
\text { Drepanosiphum platanoidis (Schrk.) }\end{array}$ & & +++ & & & & \\
\hline $\begin{array}{l}\text { Włochatka klonowa czarna } \\
\text { Periphyllus testudinaceus (Fern.) }\end{array}$ & & ++ & & & & \\
\hline $\begin{array}{l}\text { Mszyca chmielowa } \\
\text { Phorodon humuli (Schrk.) }\end{array}$ & & & + & & & + \\
\hline $\begin{array}{l}\text { Mszyca bzowa } \\
\text { Aphis sambuci L. }\end{array}$ & & & & & & + \\
\hline
\end{tabular}

ROD - Rodzinne Ogrody Działkowe - family allotments

$+++>20 \%$ zgrupowania $->20 \%$ of community; $++10-20 \%$ zgrupowania $-10-20 \%$ of community; $+5-10 \%$ zgrupowania $-5-10 \%$ of community 
pruni Geoffroy, 1762), mszycę porzeczkowo-mleczową (Hyperomyzus lactucae Linnaeus, 1758), mszycę wiśniową (Myzus cerasi Fabricius, 1775) i mszycę chmielową (Phorodon humuli Schrank, 1801). W drugiej grupie znalazły się: mszyca bzowa (Aphis sambuci Linnaeus, 1758), Brachycaudus divaricatae Shaposhnikov, 1956, Chaitophorus leucomelas Koch, 1854, zdobniczka jaworowa (Drepanosiphum platanoidis Schrank, 1801), mszyca świerkowo-szpilkowa (Elatobium abietinum Walker, 1849), bawełnica wiązowo-porzeczkowa (Eriosoma ulmi Linnaeus, 1758), zdobniczka lipowa (Eucalipterus tiliae Linnaeus, 1758), Euceraphis betulae, włochatka klonowa czarna (Periphyllus testudinaceus Fernie, 1852) i bawełnica wiązowo-zbożowa (Tetraneura ulmi Linnaeus, 1758).

Zdecydowanie najliczniej odławianym gatunkiem była mszyca czeremchowo-zbożowa ( $R$. padi). W badanych sezonach zajmował on w zgrupowaniach mszyc pozycję eudominanta (> 20\% zgrupowania) lub dominanta (10-20\% zgrupowania) w zależności od stanowiska (tab. 2). W pierwszym roku badań było to od 60,8 do 87,3 procent wszystkich zebranych w próbach uskrzydlonych morf. Udział tego gatunku w drugim roku badań był znacznie niższy i wynosił od 11 do 39,6 procent. Gatunek ten był również najliczniej odławiany w badaniach prowadzonych $\mathrm{w}$ innych obiektach terenów zieleni Poznania np. Ogrodzie Dendrologicznym, Ogrodzie Botanicznym Uniwersytetu im. Adama Mickiewicza, czy innych parkach miejskich (Wilkaniec 2001, 2004; Wilkaniec i wsp. 2005, 2007; Ratajczak i wsp. 2011). Potwierdzają to także wyniki badań Strażyńskiego (2006), Strażyńskiego i wsp. (2011) oraz Gałuszki i wsp. (2015) z wykorzystaniem odłowu mszyc przy pomocy aspiratora Johnsona.
W niniejszych badaniach licznie reprezentowany był w próbach także zrostek świdwowo-zbożowy (A. corni), którego udział w zależności od stanowiska i roku wynosił 5,9-40\%. Badania prowadzone wcześniej w terenach zieleni Poznania przez Wilkaniec i wsp. (2012) wskazują również na znaczny udział tego gatunku w materiale zebranym za pomocą pułapek Moerickego i pułapek świetlnych. W grupie gatunków występujących licznie w ogrodach działkowych i przekraczających liczebność od 5 do ponad 20 procent badanych zgrupowań, ale występujących jedynie na niektórych stanowiskach i w latach, znalazły się jeszcze 4 kolejne taksony. Były to: zdobniczka jaworowa (D. platanoidis), włochatka czarna (P. testudinaceus), mszyca chmielowa ( $P$. humuli) i mszyca bzowa (A. sambuci).

\section{Wnioski / Conclusions}

1. Na terenie rodzinnych ogrodów działkowych w Poznaniu na podstawie badań prowadzonych metodą pułapek Moerickego stwierdzono aktywność lotów 144 gatunków mszyc.

2. Odnotowano wyraźną dominację dwóch gatunków: $R$. padi oraz A. corni w stosunku do ogółu odłowionych mszyc w poszczególnych latach badań.

3. Wśród 22 gatunków mszyc obecnych na wszystkich stanowiskach i w obu latach badań znalazło się 12 ważnych gospodarczo szkodników roślin uprawnych i 10 gatunków dendrofilnych.

\section{Literatura / References}

Bennewicz J. 2010. Aphids (Hemiptera: Aphididae) of midfield thickets in agricultural landscape catches in Moericke traps. Polish Journal of Entomology 79 (2): 139-163.

Blackman R.L., Eastop V.F. 1994. Aphids on the World's Trees. An Identification and Information Guide. CAB Intertional, Wallingford, UK, $986 \mathrm{pp}$.

Cichocka E., Goszczyński W. 1991. Mszyce zasiedlające drzewa uliczne w Warszawie. s. 9-18. W: „Mszyce i ich bionomia, szkodliwość i wrogowie naturalni" (E. Cichocka, red.). PAN, Warszawa, 119 ss.

Durak R., Wojciechowski W. 2008. Structure and dynamics of aphids communities connected with trees in selected forest associations. Polish Journal of Entomology 77 (2): 79-92.

Gałuszka A., Drzewiecki S., Wolski A. 2015. Dynamika lotów ważniejszych gospodarczo gatunków mszyc odławianych w latach 2007-2011 przy użyciu aspiratora Johnsona na terenie województwa śląskiego. [Flight dynamic of economically important aphid species collected in 2007-2011 in the Silesian Province using a Johnson's aspirator]. Progress in Plant Protection 55 (2): $216-220$.

Jaśkiewicz B. 1997. Skład gatunkowy i dynamika pojawu mszyc na wybranych krzewach ozdobnych w latach 1973-1993. Rozprawy Naukowe 183. Akademia Rolnicza, Lublin, 93 ss.

Mackoś-Iwaszko E., Lubiarz M., Karczmarz K. 2015. The impact of urban conditions on the occurrence of aphids on Acer platanoides L. Acta Scientiarum Polonorum Hortorum Cultus 14 (5): 189-207.

Ratajczak J., Wilkaniec B., Wilkaniec A. 2011. Infestation of dendrological collection in central Poland by aphids. Dendrobiology 66: 85-97.

Ruszkowska M., Wilkaniec B. 2002. Urban fauna of aphids (Homoptera, Aphidoidea) related to trees and shrubs in the Poznań district. Journal of Plant Protection Research 42 (3): 205-214.

Strażyński P. 2006. Znaczenie rejestracji lotów ważniejszych gospodarczo gatunków i form mszyc w odłowach aspiratorem Johnsona w Poznaniu w latach 2003-2005 w integrowanych metodach ochrony roślin. [The importance of registration of flights of the economically important species and forms of aphids in Johnson's suction trap in Poznań in 2003-2005 in integrated pest management]. Progress in Plant Protection/Postępy w Ochronie Roślin 46 (2): 395-398.

Strażyński P., Ruszkowska M., Węgorek P. 2011. Dynamika lotów mszyc w latach 2008-2010 najliczniej odławianych w Poznaniu aspiratorem Johnsona. [Flights dynamics of aphids caught numerously by Johnson's suction trap in Poznań in 2008-2010]. Progress in Plant Protection/Postępy w Ochronie Roślin 51 (1): 213-216.

Taylor L.R. 1984. A Handbook for Aphid Identification. Rothamsted Exp. Station, Harpenden, UK, 171 pp. 
Wilkaniec B. 1999. Występowanie mszyc (Homoptera, Aphidodea) w zadrzewieniach i zakrzewieniach śródmiejskich Poznania. [Occurrence of aphids (Homoptera: Aphidodea) on selected tree and shrub species in the urban area of Poznań]. Wiadomości Entomologiczne 18 (3): 135-142.

Wilkaniec B. 2001. Afidofauna Ogrodu Dendrologicznego w Poznaniu. [Aphidofauna of Dendrological Garden in Poznań]. s. 32-37. W: „Bioróżnorodność i ekologia populacji zwierzęcych w środowiskach zurbanizowanych” (P. Indykiewicz, T. Barczak, G. Kaczorowski, red.). NICE, Bydgoszcz, 297 ss.

Wilkaniec B. 2004. Afidofauna Ogrodu Botanicznego w Poznaniu. [Aphidofauna of the Botanical Garden in Poznań]. s. 176-177. W: „Fauna miast Europy Środkowej 21. wieku” (P. Indykiewicz, T. Barczak, red.). LOGO, Bydgoszcz, 584 ss.

Wilkaniec B., Lewandowski R., Borowiak-Sobkowiak B. 2012. The effectiveness of catching aphids (Hemiptera: Sternorrhyncha: Aphidinea) in Moericke and light traps. Journal of Plant Protection Research 52 (2): 252-256.

Wilkaniec B., Piekarska-Boniecka H., Trzciński P. 2005. Mszyce jako stały element entomofauny zieleni parkowej Poznania. [Aphids as a permanent component of entomofauna in the green area of Poznań]. Progress in Plant Protection/Postępy w Ochronie Roślin 45 (1): 516-523.

Wilkaniec B., Ratajczak J., Sztukowska K. 2007. Aphid males in urban green space. p. 83-90. In: Aphids and Other Hemipterous Insect 13. Katolicki Uniwersytet Lubelski, Lublin, $226 \mathrm{pp}$. 